\title{
Variation of performance, of self-reported alertness and effort as a function of low doses of alcohol and of driving experience
}

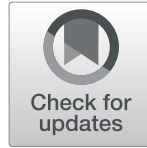

\author{
Catherine Berthelon $^{1^{*}}$ (D) and Edith Galy ${ }^{2}$
}

\begin{abstract}
Purpose: Alcohol is the most frequent detected substance in the automobile fatal crashes but its precise mode of action on mental state is not always clear, notably when combined with lack of driving experience. The aim of this work is thus to evaluate performance and self-reported alertness and effort as a function of low doses of Blood Alcohol Concentration (BAC) and of drivers' experience.

Methods: A single blind counterbalanced experiment was conducted on a driving simulator. Fifteen young novice drivers (18 years old, less of 2 months of driving licence) and fifteen young experienced drivers (21 years old, 3 years of driving licence) were tested with $0.0 \mathrm{~g} / \mathrm{l}, 0.2 \mathrm{~g} / \mathrm{l}$ and $0.5 \mathrm{~g} / \mathrm{l}$ of alcohol at early afternoon. Driving scenarios was road tracking during $45 \mathrm{~min}$ at a constant speed of $110 \mathrm{~km} / \mathrm{h}$ while maintaining a steady trajectory. Participants responded to the Thayer's scale before and after each driving session, and to an adaptation of the NASA-TLX after each driving session. Statistical analyses were performed on driving parameters, self-reported alertness and effort as a function of alcohol level and driving experience.

Results: Alcohol deteriorated lateral and longitudinal stability of the trajectories. Notably with BAC $0.5 \mathrm{~g} / \mathrm{l}$, effort and speed increased but the increase in speed was particularly high for young experienced drivers. When young novice drivers felt that they were low alert, they also felt that they exerted more effort, their performance decreased, but they reduced their speed.

Conclusions: Alcohol thus degrades driving performance, and especially when the effort is high and alertness is low. The decrease of inhibitory process noted in presence of alcohol seems thus higher for young experienced than for young novice drivers. Results are in line with a drop in the blood alcohol level tolerated while driving.
\end{abstract}

Keywords: Young drivers, Alcohol, Driving simulator, Subjective alertness, Subjective effort performance

\section{Introduction}

Young novice drivers have a high risk of crashes, notably during the first years of driving [34, 35]. Their risk of being involved in fatal crashes, relative to the number of travelled kilometers, may be estimated as being three times greater than for experienced drivers, so road crashes are the first cause of death in young people between 18 and 25 years of age [62]. They are also overrepresented in

\footnotetext{
* Correspondence: catherine.berthelon@ifsttar.fr

'TS2-LMA, Univ Gustave Eiffel, IFSTTAR, 304 Chemin de la Croix-Blanche, F-13300 Salon de Provence, France

Full list of author information is available at the end of the article
}

fatigue-related crashes [50] and crashes related to a long driving period or night driving [64].

The occurrence of drowsiness during driving is subsequently a serious problem in transportation systems and it is well known that the major part of sleep (or fatigue)related crashes takes place during the two periods of physiological decrease of alertness (early morning hours 2:00-6:00 a.m. and afternoon period 1:00-4:00 p.m.) [12, $22,42]$. The alertness decrement can be due to accumulated fatigue (time-on-task effect, for example due to long driving period) and/or to circadian biological rhythms (time-of-day effect) [33, 56]. Thus, in general,

\section{Springer Open}

(ㅇ The Author(s). 2020 Open Access This article is licensed under a Creative Commons Attribution 4.0 International License, which permits use, sharing, adaptation, distribution and reproduction in any medium or format, as long as you give appropriate credit to the original author(s) and the source, provide a link to the Creative Commons licence, and indicate if changes were made. The images or other third party material in this article are included in the article's Creative Commons licence, unless indicated otherwise in a credit line to the material. If material is not included in the article's Creative Commons licence and your intended use is not permitted by statutory regulation or exceeds the permitted use, you will need to obtain permission directly from the copyright holder. To view a copy of this licence, visit http://creativecommons.org/licenses/by/4.0/. 
time-on-task, time-on-day and monotonous environment have been found to contribute to alertness decrement.

The decrease of alertness is also related to the exigence of the task. Thus, a task requiring a sustained mental effort can influence the level of alertness and the first effects of fatigue and drowsiness can rapidly occur [27], even after 20-25 min of driving [13, 23]. For example, long periods of driving on the highway [7], notably with smooth traffic requires sustained attention which is difficult to maintain because the activity becomes almost automatic. Similarly, when the driving situation is complex, the situation requires many attentional resources to process the information of the environment and vehicle. In these two cases, accumulated fatigue increases quickly and driver's alertness decreases.

Meister's [36] model makes it possible to establish the relationship between the level of alertness, the exigency of the situations and the performance, via the workload. Thus, driving on a monotonous highway with low traffic requires that the individual provides a significant and constant effort [58] to fight against the decline of alertness, resulting in a significant mobilization of resources and therefore a high workload [53]. Effort thus corresponds to the cost represented by task execution for individual $[19,20]$. Indeed, when mental effort due to the driving task is too high or conversely is not enough to ensure adequate driving performance [5], accident can occur $[8,10]$. This suggests that task demand refers to the intrinsic features of the task while task load describes the subjective impact on the operator [6] and refers to the perceived relationship between the amount of mental processing capability or resources and the amount of resources required by the task. Therefore, measuring workload requires taking into account factors characterizing the task and factors describing how the driver engages in and allocates his/her resources for the processing of the task [47]. In the resource perspective, the level of the driver skill, e.g. driving experience [43], and the extent to which cognitive processing is automatic or controlled must thus be taken into account. Therefore, when driving in a monotonous road environment during a long time, workload can be high and performing the task can require high effort to stay awake, and associated to a decrease of driving performance, particularly for novice drivers [54]. Limited automation of driving routines could explain this higher risk of novice drivers [14], which report a higher mental workload compared to experienced drivers [11, 43]. Thus, if the drivers have to provide a high effort to overcome the alertness decrement, this effort is more important for novices because they have not completely automatized driving tasks [18]. Otherwise, when alertness is low the effort of novice drivers can be too high to maintain good performance. The assessment of mental effort invested to perform task can therefore be a valuable tool to investigate potentially dangerous driving situations $[1,45]$.

Moreover, alcohol represents as one major factor of driving impairment and a clear relationship exists between blood alcohol concentration (BAC) and crash risk notably at BAC larger than from $0.5 \mathrm{~g} / \mathrm{l}$. Alcohol alters the cognitive and motor functions necessary to safe driving and exacerbates the effect of drowsiness [17, $28,29,48,59]$. This implies a probable link with the fact that alcohol-related accidents are mainly due to a loss of control of the driver [38]. Studies also permit to suggest that the $0.5 \mathrm{~g} / \mathrm{l}$ threshold tolerated by french law when driving a vehicle be lower for young drivers [4, 46, 49, 65]. In particular, past studies showed that alcohol has differential effect as a function of young drivers' experience [2, 17].

The main objective of the present study was to evaluate the combined effect of some major factors of accident, low doses of alcohol and driving experience, on young drivers' performance and self-report of effort and alertness, during a long monotonous driving task. We used techniques of direct recordings of the driver's performance in a simulator and questionnaires. The first hypothesis is that, even in case of low alcohol intoxication, when alertness is known to be low (early afternoon) and during long and monotonous driving task, driving impairment is higher for young novice drivers than for young experienced drivers. The second hypothesis is that an increase of effort decreases alertness, notably when drivers lack of experience and/or in presence of alcohol.

\section{Materials and methods}

\subsection{Participants}

Fifteen young novice drivers (YND, 8 males and $7 \mathrm{fe}$ males, 18 years, less than 2 months of driving license,) and fifteen young experienced drivers ${ }^{1}$ (YED, 8 males and 7 females, 21 years, 3 years of driving license) participated in three simulated driving sessions in which BACs were randomly manipulated $(0.0,0.2$ and $0.5 \mathrm{~g} / \mathrm{l})$. Participants underwent a medical examination in order to confirm their good physical condition, the absence of any sleep disorder and of any medical treatment at the time of their inclusion in the experiment and during the previous 15 days. Only social drinkers, defined as individuals with moderate alcohol consumption (i.e., $\leq 2$ standard drinks/day, often in a socially acceptable situation) were included in the experiment. They gave written informed

\footnotetext{
${ }^{1}$ In France, drivers are considered as novices for 3 years after acquiring their driving license if they followed a traditional training method, this period is called probationary license. Several restrictions are associated with the probationary license, notably it has an initial capital of 6 points instead of 12 points.http://www.securite-routiere.gouv.fr/ permis-de-conduire/le-permis-a-points/le-permis-probatoire
} 
consent and signed informed commitment prior to inclusion. They received a compensation for their participation.

The study granted ethical approval by the French local ethics committee and by the French Health Products Safety Agency (number ID RCB: 2014-A00350-47).

\subsection{Design}

We conducted the study according to a balanced, single blind, crossover design. Each participant followed three experimental sessions balanced for order. Before each session, they drank a beverage (vodka $40^{\circ}$ and/or orange juice) in order to obtain a BAC of $0.0,0.2$ or $0.5 \mathrm{~g} / \mathrm{l}$. To make the BAC $0.0 \mathrm{~g} / \mathrm{l}$ condition more convincing, alcohol odors (tissue scented with vodka) were rubbed on the top of the edge of the glass in which the drinks were given. One of our previously published article [3] describes the calculation of alcohol dose necessary to obtain the expected BAC. Briefly, it takes into account the sex, age, weight and height of the participants. Experimental sessions began around at $1 \mathrm{pm}$ and a washout period of at least 2 days separated them. Participants had only a breakfast before the experimental sessions.

The duration of drinking was around $15 \mathrm{~min}$ (min). Time between the end of alcohol intake and driving was around $30 \mathrm{~min}$ and preceded by a verification of the BAC measured with a breath analyzer (SD-400 DJP/ LION). The blood alcohol levels obtained just before driving were as expected (Table 1).

\subsection{Apparatus}

We carried out the driving experiment on the fixed base-driving simulator of Ifsttar/TS2/LMA in Salon de Provence (Fig. 1). The driving station is a complete vehicle (Renault Megane) equipped with two lateral (left and right) and one central rear-view mirrors. Drivers manage the vehicle by moving a steering wheel and manipulating the accelerator, gear lever and brake pedals. Force feedback is provided on the steering wheel and auditory feedback of the motor was provided. The images are generated at a frequency of $60 \mathrm{~Hz}$. The road scenario was projected onto five large screens, providing a 200-degree horizontally and 40-degree vertically field of view, showing a very realistic scene. The simulator allows the continuous recording of parameters that describe the vehicle travelling conditions, including speed and lane position.

\subsection{Procedure}

We used the same driving scenario for the three BAC sessions. It consisted of a two-lane mostly straight rural highway, with a few curves, no traffic density in a relatively flat environment. Before each session, participants were trained to the command of the simulator. The task consisted of drive during $45 \mathrm{~min}$ and to maintain a steady speed $(110 \mathrm{~km} / \mathrm{h})$ and a stable position on the lane. This kind of monotonous driving task is very sensitive to study attentional processes, arousal and alertness decreasing, and to study the effect of psychoactive substances like alcohol. A duration of $45 \mathrm{~min}$ is largely enough to obtain the first effect of drowsiness [13, 56], even with low doses of alcohol $[28,29,59]$.

\subsection{Measures}

\subsubsection{Objective measures of performance}

Behavioral variables considered were the Standard Deviation of Lateral Position (SDLP), i.e., the "weaving" of the car, the speed (speed) and standard deviation of speed (SDspeed). Under the influence of alcohol, drivers experience an increase in the variability of lateral and longitudinal performance of their vehicle (for a review see [30]).

\subsubsection{Subjective measures}

Participants reported their subjective alertness with Thayer checklist [55] before and after each driving session, and their workload with NASA-TLX questionnaire after each session [25]. Thayer checklist comprises 20 adjectives corresponding to 4 dimensions (general activation, hyper-activation, general deactivation, deactivation sleep). The ratio of general activation on deactivation sleep allows calculating an alertness index, and the ratio of hyper-activation on general deactivation allows calculating a tension index. Six sub-scales composes NASA-TLX questionnaire: mental demand, physical demand, temporal demand, effort, frustration and own performance. Given the objectives of this paper only the alertness index of Thayer's questionnaire before and after driving was treated. Concerning the NASA-TLX, we considered the only effort sub-dimension of NASATLX. Indeed, Galy, Paxion and Berthelon [21] recommends the distinction of each dimension of NASA-TLX rather than the use of global score. In that study, effort dimension was determined by physical and mental demands and by alertness and, was the only dimension

Table 1 Mean BACs measured prior and following the drive as a function of experience (SD between brackets)

\begin{tabular}{|c|c|c|c|c|}
\hline & \multicolumn{2}{|l|}{$0.2 \mathrm{~g} / \mathrm{l}$} & \multicolumn{2}{|l|}{$0.5 \mathrm{~g} / \mathrm{l}$} \\
\hline & prior the drive & after the drive & prior the drive & after the drive \\
\hline Young novice (YND) & $0.227(0.011)$ & $0.129(0.007)$ & $0.503(0.011)$ & $0.335(0.013)$ \\
\hline Young experienced (YED) & $0.217(0.015)$ & $0.094(0.014)$ & $0.504(0.023)$ & $0.323(0.019)$ \\
\hline
\end{tabular}




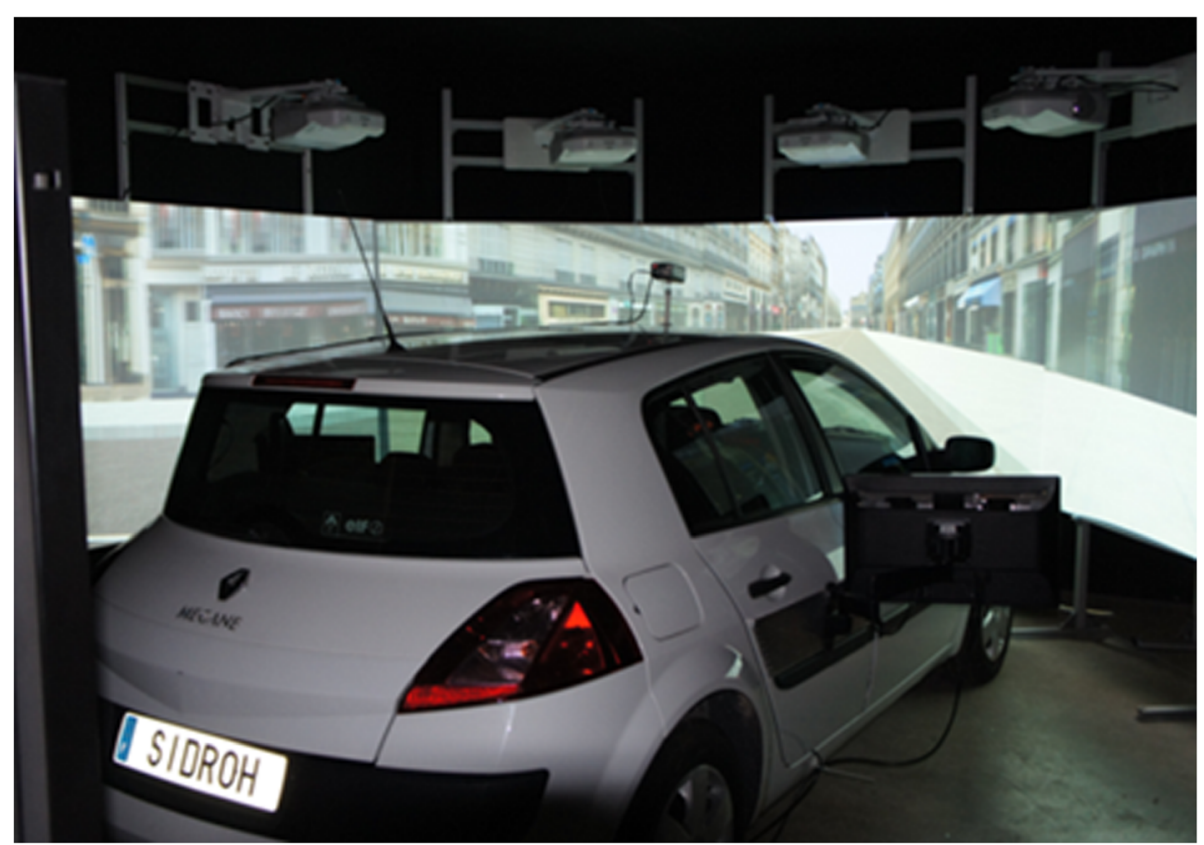

Fig. 1 The simulator used for the experiment

having a direct effect on driving performance. Thus, in present study, we made the choice to use only effort in results treatment.

\subsection{Statistical analysis}

First, ANOVA compared self-reported effort, alertness (before and after driving), speed, SDspeed and SDLP as a function of alcohol level and group. We then applied generalized linear models (GLM is a generalization of linear regression) to deepen the links between BAC, experience, objective and subjective variables. GLM make it possible to study the relationship between one dependent variable and a set of explicative variables (dependent and independent) that can be categorical and continuous. The indicator associated with each explicative variable and used to complete the weight of this variable in the explanatory model is the Khi square of Wald. In case of significant results, we completed these last analyses with correlation for continuous variables and post-hoc bonferroni tests for categorical variables. GLM were applied on each subjective and objective variable. The level of significance for analyses was set at 05 .

\section{Results}

3.1 ANOVA results: subjective and objective variables

Results of ANOVA showed a significant and systematic decrease of self-report alertness after driving sessions (F $[1,28]=102.03, p<.001, \eta^{2}=.78$; Fig. 2 ). There were no

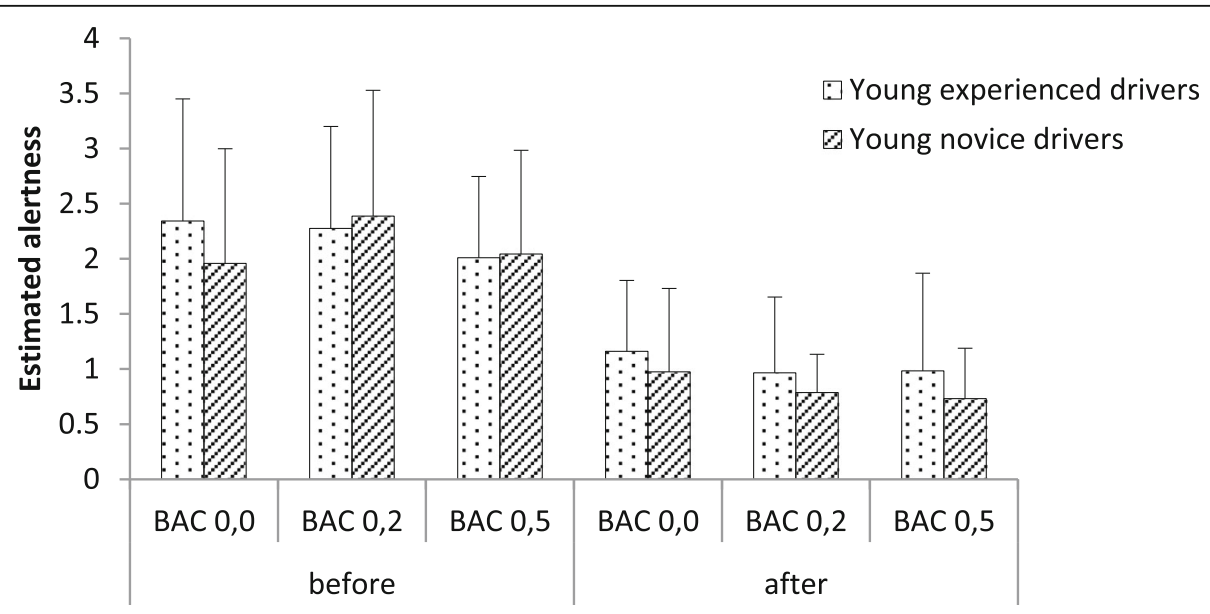

Fig. 2 Mean self-reported alertness level before and after driving session for each group and each BAC 
other significant main effects or interaction effects. From these first results, only self-reported alertness after the driving task will be considered in the GLM subsequent analyzes (part 3.2.).

ANOVA did not show any effect of experience on dependent variables (Table 2).

SDLP significantly varied with alcohol level and was lower with BAC $0.0 \mathrm{~g} / \mathrm{l}$ than with BAC $0.2 \mathrm{~g} / \mathrm{l}(p<.04)$ and $\mathrm{BAC} 0.5 \mathrm{~g} / \mathrm{l}(p<.001)$. BAC $0.2 \mathrm{~g} / \mathrm{l}$ did not differ from BAC $0.5 \mathrm{~g} / \mathrm{l}(p<.11)$.

SDspeed also significantly varied as a function of alcohol and was lower with BAC $0.0 \mathrm{~g} / \mathrm{l}$ than with BAC 0.5 $\mathrm{g} / \mathrm{l} \quad(p<.002)$; BAC $0.2 \mathrm{~g} / \mathrm{l}$ did not differ significantly from BAC $0.0 \mathrm{~g} / \mathrm{l} \quad(p<.25)$ and from BAC $0.5 \mathrm{~g} / \mathrm{l}$ $(p<.25)$.

Finally, effort is lower with BAC $0.0 \mathrm{~g} / \mathrm{l}$ than with BAC $0.5 \mathrm{~g} / \mathrm{l}(p<.03)$. BAC $0.2 \mathrm{~g} / \mathrm{l}$ did not differ significantly from BAC $0.0 \mathrm{~g} / \mathrm{l}(p<.60)$ and from BAC $0.5 \mathrm{~g} / \mathrm{l}(p<.54)$ (Table 3). No interaction effects were noted between alcohol and driving experience.

\subsection{GLM results: subjective and objective variables}

We found a significant interaction effect between driving experience and self-reported alertness after driving on perceived effort $\left(\chi^{2}(1)=22.43, \quad p<.001\right), \quad$ SDspeed $\left(X^{2}(1)=22.45, p<.001\right)$, speed $\left(\chi^{2}(1)=15.195, p<.001\right)$ and SDLP $\left(\chi^{2}(1)=40.194, p<.001\right)$. Thus, when estimated alertness decreased:

- the effort increased more for YNDs $(r=-423)$ than for YEDs $(r=-217)$,

- YNDs SDspeed and SDLP increased (respectively $r=-293$ and $r=-.296)$ and their speed decreased $(r=.220)$ (Fig. 3a and b),

- YEDs' SDspeed decreased ( $r=138$; Fig. 3a).

Results also showed significant interactions between alcohol and alertness on speed $\left(\mathrm{x}^{2}(2)=13.182, p<.001\right)$, between alcohol and effort on speed $\left(x^{2}(2)=43.65\right.$, $p<.001)$ and on SDspeed $\left(\mathrm{x}^{2}(2)=18.08, p<.001\right)$. Thus with BAC $0.0 \mathrm{~g} / \mathrm{l}(r=.292)$ and BAC $0.2 \mathrm{~g} / \mathrm{l}(r=.352)$ a low self-reported alertness was associated to an decrease of speed, and an increase of effort produced a decrease of speed (BAC $0.0 \mathrm{~g} / \mathrm{l}, r=-.169$ and BAC $0.2 \mathrm{~g} / \mathrm{l}, r=$
-.258). Conversely, with BAC $0.5 \mathrm{~g} / \mathrm{l}$ an increase of effort was associated to an increase of speed $(r=.300)$. Finally, with BAC $0.0 \mathrm{~g} / \mathrm{l}(r=.173)$ and BAC $0.5 \mathrm{~g} / \mathrm{l}(r=.210)$ an increase of effort was also associated to an increase of SDspeed, but with BAC $0.2 \mathrm{~g} / \mathrm{l}(r=-.169)$ an increase of effort produced a decrease of SDspeed.

Analyses revealed a significant interaction effect between driving experience and alcohol on SDspeed $\left(\chi^{2}(2)=6.89, p<.032\right)$, on perceived effort $\left(\chi^{2}(2)=21.17\right.$, $p<.001)$ and another interaction tended to be significant $\left(\chi^{2}(2)=5.07, p<.061\right)$.

YEDs' estimated higher effort with BAC $0.2 \mathrm{~g} / \mathrm{l}$ and BAC $0.5 \mathrm{~g} / \mathrm{l}(p<.001)$ than with BAC $0.0 \mathrm{~g} / 1$ and their SDspeed was thus higher with BAC $0.2 \mathrm{~g} / \mathrm{l}$ and BAC 0.5 $\mathrm{g} / \mathrm{l}$ than with BAC $0.0 \mathrm{~g} / \mathrm{l}$ (respectively, $p<.002$ and $p<.001$, Fig. 4a). Their speed was higher with BAC 0.5 $\mathrm{g} / \mathrm{l}$ than with BAC $0.2 \mathrm{~g} / \mathrm{l}(p<.006)$ and BAC $0.0 \mathrm{~g} / \mathrm{l}$ $(p<.001$, Fig. 4b).

YNDs' SDspeed was significantly lower with BAC 0.0 $\mathrm{g} / \mathrm{l}$ and BAC $0.2 \mathrm{~g} / \mathrm{l}$ than with BAC $0.5 \mathrm{~g} / \mathrm{l}$ (respectively $p<.001$ and $p<.005$, Fig. 4a) and they reported lower effort with BAC $0.2 \mathrm{~g} / \mathrm{l}$ than with BAC $0.5 \mathrm{~g} / \mathrm{l}(p<.008)$.

\section{Discussion}

The main objective of this experiment was to study the effects of low doses of alcohol and lack of experience on driving performance, and their links with self-reported effort and alertness. We assumed that taking a low dose of alcohol in the early afternoon, at the time of the low physiological alertness, and before a monotonous and long drive, leads to alertness decrease, effort increase and reduced performance, especially for young novice drivers. Two levels of driving experience (15 participants each) and three levels of BACs $(0.0,0.2$ and $0.5 \mathrm{~g} / \mathrm{l})$ were manipulated during a simulator study reproducing a monotonous circuit. We analyzed objective driving parameters and subjective alertness and effort parameters. Data were first treated by ANOVAs, which are classical statistic methods used in this kind of experiment. A generalization of linear regression were then carried out to test different models of the relationships between the dependent and independent variables and their mutual influence, some of them having a mediating role of the others.

Table 2 Mean driving performance, estimated effort and estimated alertness after driving as a function of experience (SD between brackets)

\begin{tabular}{lllll}
\hline & Young novice drivers & Young experienced drivers & $F[1,28]$ & $P<$ \\
\hline SDLP $(\mathrm{cm})$ & $49.72(20.31)$ & $47.65(13.34)$ & .24 & .62 \\
Speed $(\mathrm{m} / \mathrm{s})$ & $30.22(1.08)$ & $30.28(.68)$ & .1 & .01 \\
SDspeed $(\mathrm{m} / \mathrm{s})$ & $.99(.77)$ & $.87(.44)$ & .67 & .75 \\
Estimated effort (Nasa-TLX) & $12.42(4.33)$ & $12.16(2.89)$ & .04 & .42 \\
Estimated alertness (Thayer) & $0.83(.55)$ & $1.04(.73)$ & 1.18 & .00 \\
\hline
\end{tabular}


Table 3 Mean driving performance, estimated effort and estimated alertness after driving as a function of BAC (SD between brackets)

\begin{tabular}{llllll}
\hline & BAC $0.0 \mathrm{~g} / \mathrm{l}$ & BAC $0.2 \mathrm{~g} / \mathrm{l}$ & BAC 0.5 g/l & $\mathrm{F}[2,56]$ & $P<$ \\
\hline SDLP $(\mathrm{cm})$ & $42.14(12.66)$ & $48.74(14.63)$ & $55.27(20.76)$ & 10.89 & .001 \\
Speed $(\mathrm{m} / \mathrm{s})$ & $30.17(0.81)$ & $30.18(0.74)$ & $30.40(1.06)$ & 1.56 & .23 \\
SDspeed $(\mathrm{m} / \mathrm{s})$ & $0.76(0.56)$ & $0.93(0.55)$ & $1.10(0.72)$ & 6.25 & .05 \\
Estimated effort (Nasa-TLX) & $11.31(4.76)$ & $12.27(3.66)$ & $13.28(3.81)$ & 3.51 & .003 \\
Estimated alertness (Thayer) & $1.07(0.69)$ & $0.88(0.54)$ & $0.86(0.69)$ & 1.66 & .04 \\
\hline
\end{tabular}

As expected, results indicated a lower level of alertness after the drive than before the drive. Globally, young novice and young experienced drivers' performance, alertness and effort did not differ significantly. We thus assume that obtaining a driving license at 18 years could be sufficient to acquire basic abilities necessary to drive in a monotonous environment. However, a more indepth analysis of the results modulates this first statement. Thus, when YNDs estimated to be very alert, their speed was higher and the longitudinal and lateral stability of their vehicle is better. Conversely, when their estimation of alertness was low, their effort to maintain good performance was very high and the lateral (SDLP) and longitudinal (SDspeed) stability of their trajectory were affected though they adjust their speed accordingly by reducing it. The driving task seems them difficult due to their limited driving experience but they are aware of their lack of skills and adopt a lower speed than more experienced drivers. YNDs' thus decrease task demands to fit their (deficient) level of automated driving by reducing speed which give them more time to react to road event and can be consider as a regulatory mechanism to maintain performance $[9,18]$. Conversely to YNDs', in case of low alertness, YEDs' increase of effort is linked to an improvement of the longitudinal trajectory. This suggested that YEDs' decrease of alertness is compensated by the effort and permits to maintain good performance as postulated by Meister model [36]. Thus, for individuals with higher cognitive resources at their disposal, e.g. YED, the task can felt to be easier, the workload is lower and requires less effort to be well realized $[15,44,45]$.

The behavioral parameters varied as a function of alcohol level, confirming their sensibility to deleterious effect of alcohol in simulated driving [26, 30, 39, 41]. They clearly established the capacity of alcohol to impair several basic driving skills $[3,24,31,40,52,57,61]$ and converged to an increase of risky driving whatever the level of driving experience [32,37]. Thus, the stability of the trajectories both on the lateral and on the longitudinal parameters deteriorated with alcohol, notably with BAC $0.5 \mathrm{~g} / \mathrm{l}$. Looking more deeply on results confirm that effort and alertness have separated effects on driving parameters concerning alcohol. All the participants

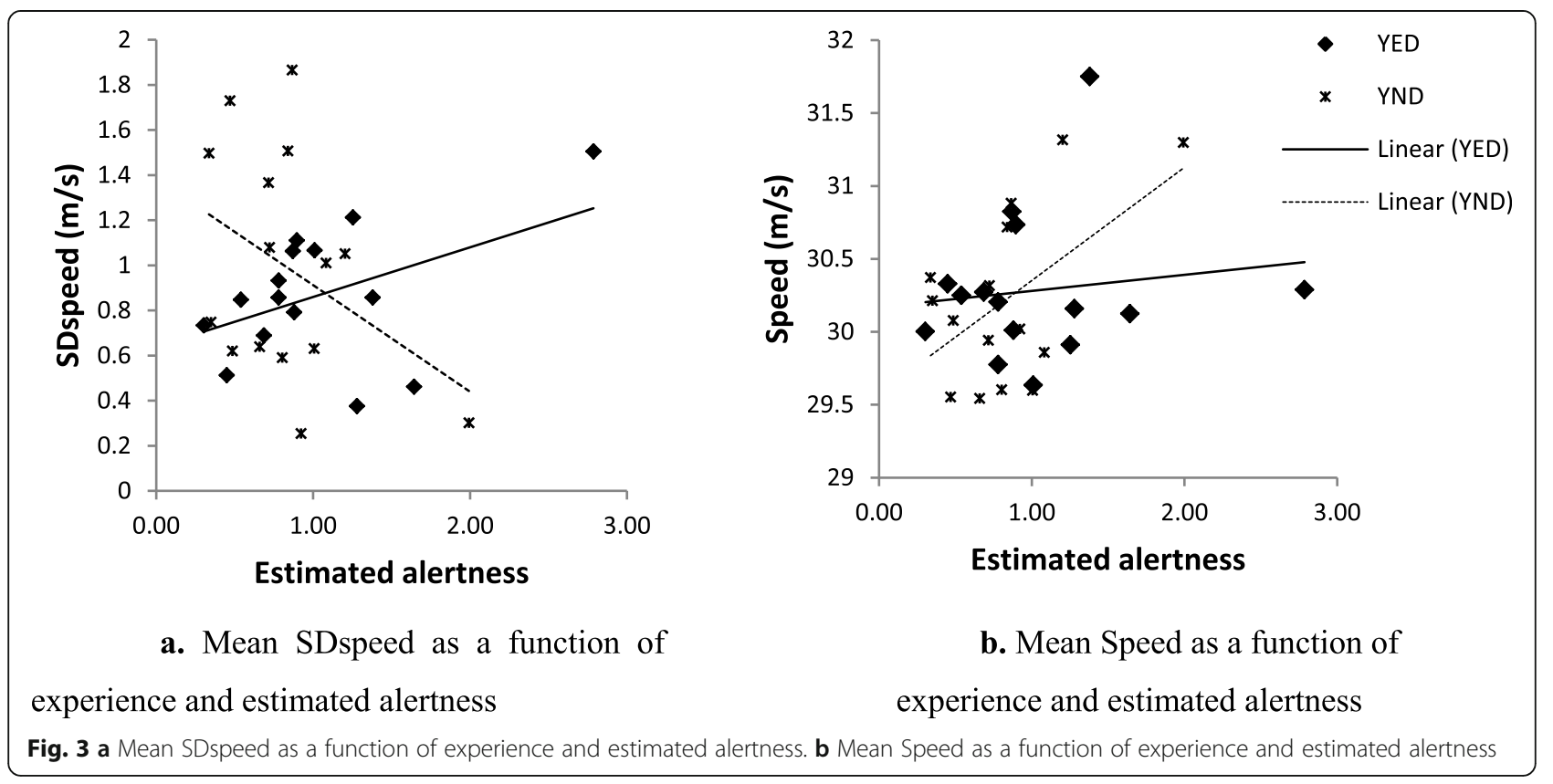




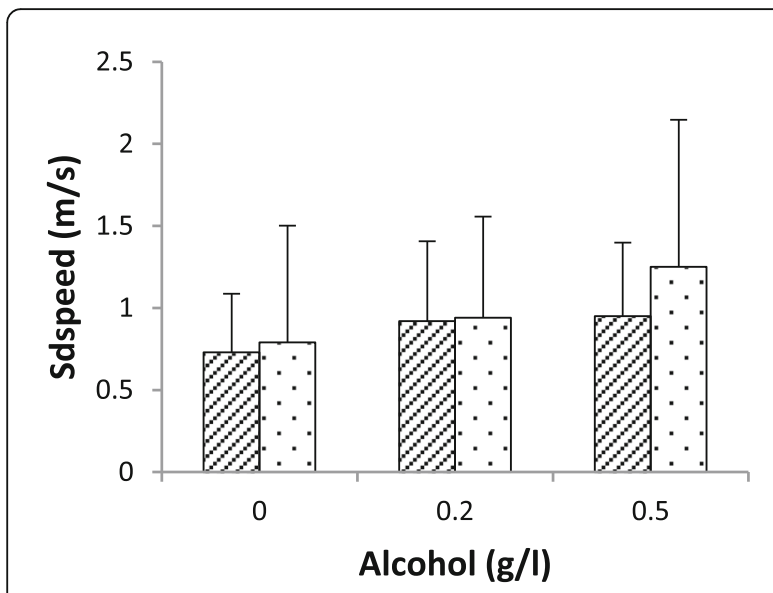

a. Mean SDspeed as a function of alcohol and experience

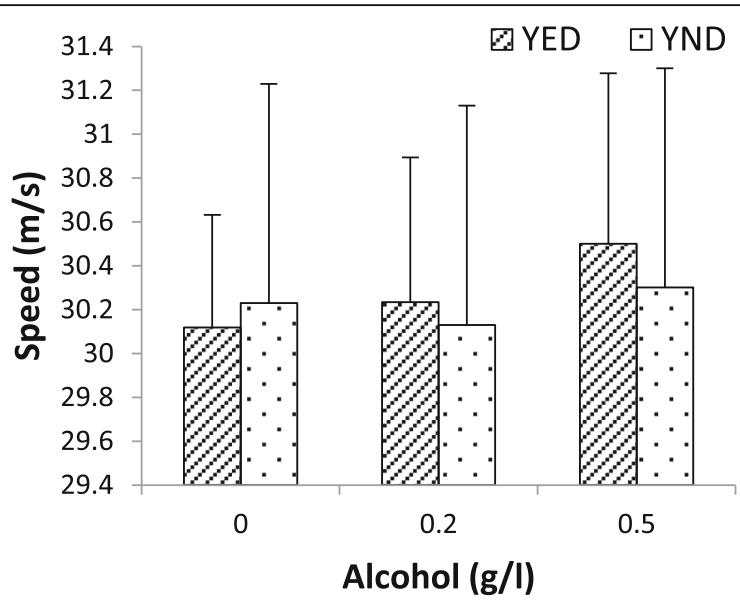

b. Mean speeds as a function of alcohol and experience.

Fig. 4 a Mean SDspeed as a function of alcohol and experience. b Mean speeds as a function of alcohol and experience

reported to make higher effort with BAC $0.5 \mathrm{~g} / \mathrm{l}$ than with no alcohol consumption, this higher effort results in a higher speed and a lower stability of the longitudinal trajectory. Alcohol thus produces a decline of inhibitory processes $[16,63]$ on drivers' speed and promotes the tendency of young people to drive at high speeds. Conversely, with BAC $0.0 \mathrm{~g} / \mathrm{l}$ and $\mathrm{BAC} 0.2 \mathrm{~g} / \mathrm{l}$, when the participants estimated to be less alert or to make a great effort their speed decreased, although the stability of their longitudinal trajectory is not always improved (high SDspeed without alcohol). This decrease of speed can be considered as a compensatory mechanism as postulated by Meister [36].

Otherwise, at first, the lack of interaction between the level of experience and alcohol looked contradictory with the blood alcohol level of $0.2 \mathrm{~g} / \mathrm{l}$ tolerated by law only for French novice drivers and during 3 years. However, YEDs estimate higher effort with BAC 0.5 and 0.2 $\mathrm{g} / \mathrm{l}$ than without alcohol and they practice higher speed with BAC $0.5 \mathrm{~g} / \mathrm{l}$ while the longitudinal stability of their trajectory is deteriorating from BAC $0.2 \mathrm{~g} / \mathrm{l}$. On contrary, YNDs only estimated higher effort with BAC $0.5 \mathrm{~g} / \mathrm{l}$ than with BAC $0.2 \mathrm{~g} / \mathrm{l}$ but their speed did not grow. They just had more difficulty to stabilize it (high SDspeed). It thus seems that the decrease of inhibitory process noted in presence of alcohol is higher for YEDs than for YNDs. As a result, the levels of BAC tolerated by French legislation could be lowered for all young drivers.

Current analyses underline the interest to study the combined effect of different factors influencing driving performance. They also highlight that learning to drive is complex and is not limited to a few hours in driving school before obtaining the license but builds itself over time and is constantly changing. It must also be underlined that this work does not make it possible to differentiate between changes due to capacity and those due to age, either in terms of driving behavior or in terms of awareness of one's internal state. At this stage, we are no longer able to say if the modifications of performance noted in this study can be translate into real crash and to the entire driver population. Note finally that here alcohol was ingested in the early afternoon (time of a low physiological alertness related to circadian rhythms) which can have amplified the alertness decrement.

It could also be argued that a part of our data are subjective but subjects' self-reported level of alertness are coherent with the effect of alcohol as measured by physiological measures (EEG) which shows an objective decrease of alertness with alcohol $[28,59]$. Finally, this study considers driving after alcohol consumption, in the descending limb of the BAC curve, coherent with the fact that decisions to drive often occur as BAC is declining. However, it could be that the stimulating effect of alcohol could be higher during the ascending limb of the BAC curve [51,60]. Our next step will therefore be to test a group of older drivers in the ascending and descending phases following the consumption of low doses of alcohol.

\section{Conclusions}

These results are in line with past results showing that low doses of alcohol (BAC $0.5 \mathrm{~g} / \mathrm{l}$ ) decrease objective performance such as the longitudinal and lateral parameters of the trajectory, as it is the case for our two groups of young drivers. However, the internal state, estimated by alertness and effort, have balanced effects on the driving performance and alcohol as a function of 
driving experience. In particular, with $\mathrm{BAC} 0.5 \mathrm{~g} / \mathrm{l}$ a greater effort is required to maintain performance and leads to a decrease of inhibitory process, e.g. a higher speed, especially for YEDs. This last finding could be included in the list of factors explaining excessive speed in a part of the young drivers' population.

\section{Acknowledgments}

The authors thank Laurent Ferrier for making passed this experiment and participating in the preliminary treatments of the data.

\section{Authors' contributions}

The two authors made substantial contributions to the design of the work helped to the interpretation of data and substantively revised the work. They read and approved the manuscript.

\section{Funding}

This work was supported by the Fondation Sécurité Routière (French Road Safety Foundation), Convention 2013/MP/03.

\section{Availability of data and materials}

The datasets generated during and/or analysed during the current study are available from the corresponding author on reasonable request.

\section{Competing interests}

The authors declare that they have no competing interests.

\section{Author details}

'TS2-LMA, Univ Gustave Eiffel, IFSTTAR, 304 Chemin de la Croix-Blanche, F-13300 Salon de Provence, France. 'LAPCOS, University of Côte d'Azur, 06357 Nice, France.

\section{Received: 15 January 2020 Accepted: 22 May 2020}

Published online: 26 May 2020

\section{References}

1. Albentosa, J., Galy, E., \& Berthelon, C. (2017). Complexité des situations, expérience, charge de travail, tension et vigilance : quels impacts sur les performances de conduite? Le Travail Humain, 80(4), 395-416.

2. Berthelon, C., \& Galy, E. (2018). Is the driving behaviour of young novices and young experienced drivers under alcohol linked to their perceived effort and alertness? In N. Stanton (Ed.), Advances in human aspects of transportation. AHFE 2017. Advances in intelligent systems and computing (Vol. 597, pp. 878-883). Cham: Springer.

3. Berthelon, C., \& Gineyt, G. (2014). Effects of alcohol on automated and controlled driving performance. Psychopharmacology, 231, 2087-2095.

4. Blomberg, R. D., Peck, R. C., Moskowitz, H., Burns, M., \& Fiorentino, D. (2009). The Long Beach/Fort Lauderdale relative risk study. Journal of Safety Research, 40, 285-292.

5. Brookhuis, K. A., \& De Waard, D. (2010). Monitoring drivers' mental workload in driving simulators using physiological measures. Accident; Analysis and Prevention, 42, 898-903.

6. Brookhuis, K. A., Van Driel, C. J. G., Hof, T., Van Arem, B., \& Hoedemaeker, M. (2008). Driving with a congestion assistant; mental workload and acceptance. Applied Ergonomics, 40, 1019-1025.

7. Campagne, A., Pebayle, T., \& Muzet, A. (2004). Correlation between driving errors and vigilance level: influence of the driver's age. Physiology \& Behavior, 80, 515-524.

8. Chiron, M., Bernard, M., Lafont, S., \& Lagarde, E. (2008). Tiring job and work related injury road crashes in the GAZEL cohort. Accident; Analysis and Prevention, 40, 1096-1104.

9. Cnossen, F., Rothengatter, T., \& Meijman, T. (2000). Strategic changes in task performance in simulated car driving as an adaptive response to task demands. Transportation Research Part F: Traffic Psychology and Behaviour, 3, $123-140$.

10. De Craen, S., Twisk, D. A. M., Hagenzieker, M. P., Elffers, H., \& Brookhuis, K. A. (2008). The development of a method to measure speed adaptation to traffic complexity: identifying novice, unsafe, and overconfident drivers. Accident; Analysis and Prevention, 40, 1524-1530.
11. De Waard, D. (2002). Mental workload. In R. Fuller \& J. A. Santos (Eds.), Human factors for highway engineers (pp. 161-175). Oxford: Elsevier Science Ltd.

12. Di Milia, L., Smolensky, M. H., Costa, G., Howarth, H. D., Ohayon, M. M., \& Philip, P. (2011). Demographic factors, fatigue, and driving accidents: an examination of the published literature. Accident; Analysis and Prevention, 43, 516-532.

13. Dunn, N., \& Williamson, A. (2012). Driving monotonous routes in a train simulator: the effect of task demand on driving performance and subjective experience. Ergonomics, 55, 997-1008.

14. Engström, I., Gregersen, N. P., Hernetkoski, K., Keskinen, E., \& Nyberg, A. (2003). Young novice drivers, driver education and training. Literature review. VTI rapport 491A.

15. Fabbri, M., Natale, V., \& Adan, A. (2008). Effect of time of day on arithmetic fact retrieval in a number-matching task. Acta Psychologica, 127, 285-290.

16. Fillmore, M. T., Blackburn, J. S., \& Harrison, L. R. (2008). Acute disinhibiting effects of alcohol as a factor in risky driving behaviour. Drug and Alcohol Dependence, 95, 97-106

17. Freydier, C., Berthelon, C., Bastien-Toniazzo, M., \& Gineyt, G. (2014). Divided attention in young drivers under the influence of alcohol. Journal of Safety Research, 49, 1-18.

18. Fuller, R. (2005). Towards a general theory of driver behaviour. Accident; Analysis and Prevention, 27(3), 461-472.

19. Galy, E., Cariou, M., \& Mélan, C. (2012). What is the relationship between mental workload factors and cognitive load types? International Journal of Psychophysiology, 83, 269-275.

20. Galy, E., \& Mélan, C. (2015). Effects of cognitive appraisal and mental workload factors on performance to an arithmetic task. Applied Psychophysiology and Biofeedback, 40, 313-325.

21. Galy, E., Paxion, J., \& Berthelon, C. (2017). Measuring mental workload with the NASA-TLX needs to examine each dimension rather than relying on the global score: an example with driving. Ergonomics. https://doi.org/10.1080/ 00140139.2017.1369583.

22. Garbarino, S, Nobili, L, Beelke, M. De Carli, F, \& Ferrillo, F. (2001). The contributing role of sleepiness in highway vehicle accidents. Sleep, 24, 203-206.

23. Gershon, P., Ronen, A., Oron-Gilad, T., \& Shinar, D. (2009). The effects of an interactive cognitive task (ICT) in suppressing fatigue symptoms in driving. Transportation Research Part F: Traffic Psychology and Behaviour, 2, 21-28.

24. Harrison, E. L. R., \& Fillmore, M. T. (2011). Alcohol and distraction interact to impair driving performance. Drug and Alcohol Dependence, 117, 31-37.

25. Hart, S. G., \& Staveland, L. E. (1988). Development of NASA-TLX (task load index): results of empirical and theoretical research. Advances in Psychology, 52, 139-183.

26. Helland, A., Jenssen, G. D., Lervåg, L. D., Westin, A. A., Moen, T., Sakshaug, K Lydersen, S., Mørland, J., \& Slørdal, L. (2013). Comparison of driving simulator performance with real driving after alcohol intake: a randomised, single blind, placebo-controlled, cross-over trial. Accident; Analysis and Prevention, 53, 9-16.

27. Horne, J. A., \& Reyner, L. A. (1999). Vehicle accidents related to sleep: a review. Occupational and Environmental Medicine, 56, 289-294.

28. Horne, J. A., Reyner, L. A., \& Barrett, P. R. (2003). Driving impairment due to sleepiness is exacerbated by low alcohol intake. Occupational and Environmental Medicine, 60, 689-692.

29. Howard, M. E., Jackson, M. L., Kennedy, G. A., Swann, P., Barnes, M., \& Pierce, R. J. (2007). The interactive effects of extended wakefulness and low-dose alcohol on simulated driving and vigilance. Sleep, 30, 1334-1340.

30. Irwin, C., ludakhina, E., Desbrow, B., \& McCartney, D. (2017). Effects of acute alcohol consumption on measures of simulated driving: a systematic review and meta-analysis. Accident; Analysis and Prevention, 102, 248-266.

31. Jongen, S., Vuurman, E. F. P. M., Ramaekers, J. G., \& Vermeeren, A. (2016). The sensitivity of laboratory tests assessing driving related skills todose-related impairment of alcohol: a literature review. Accident; Analysis and Prevention, 89, 31-48.

32. Lenné, M. G., Dietze, P. M., Triggs, T. J., Walmsley, S., Murphy, B., \& Redman, J. N. (2010). The effects of cannabis and alcohol on simulated arterial driving: influences of driving experience and task demand. Accident; Analysis and Prevention, 42, 859-866.

33. Lenné, M. G., Triggs, T. J., \& Redman, J. R. (1997). Time of day variations in driving performance. Accident; Analysis and Prevention, 29, 431-437.

34. Maycock, G., \& Forsyth, E. (1997). Cohort study of learner and novice drivers, part 4: novice driver accidents in relation to methods of learning to drive, 
performance in the driving test and self-assessed driving ability and behaviour. Report no. TRL 275. Crowthorne: TRL

35. McCartt, A. T., Mayhew, D. R., Braitman, K. A., Ferguson, S. A., \& Simpson, H. M. (2009). Effects of age and experience on young driver crashes: review of recent literature. Traffic Injury Prevention, 10, 209-219.

36. Meister, D. (1976). Behavioral foundations of system development. New York: Wiley.

37. Mets, M., Kuipers, E., de Senerpont Domis, L. M., Leenders, M., Olivier, B., \& Verster, J. (2011). Effects of alcohol on highway driving in the STISIM driving simulator. Human Psychopharmacology: Clinical and Experimental, 26(6), 434-439.

38. Morland, J., Steentoft, A., Wiese Simonsen, K., Ojanpera, I., Vuori, E., Magnusdottir, K., Kristinsson, J., Ceder, G., Kronstrand, R., \& Christophersen, A. (2011). Drugs related to motor vehicle crashes in northern European countries: a study of fatally injured drivers. Accident; Analysis and Prevention, 43, 1920-1926.

39. O'Hanlon, J. F. (1984). Driving performance under the influence of drugs: rationale for, and application of, a new test. British Journal of Clinical Pharmacology, 18, 121S-129S.

40. Ogden, E. J., \& Moskowitz, H. (2004). Effects of alcohol and other drugs on driver performance. Traffic Injury Prevention, 5, 185-198.

41. Owens, K., \& Ramaekers, J. G. (2009). Drugs, driving and models to measure impairment. In J. Verster, S. R. Pandi-Perumal, J. G. Ramaekers, \& J. J. de Gier (Eds.), Drugs, driving and traffic safety (pp. 43-58). Basel-Boston-Berlin: Birkhauser Verlag.

42. Pack, A. I., Pack, A. M., Rodgman, E. A., Cucchiara, A., Dinges, D. F., \& Schwab, C. W. (1995). Characteristics of crashes attributed to the driver having fallen asleep. Accident; Analysis and Prevention, 27, 769-775.

43. Patten, C. J. D., Kircher, A., Östlund, J., Nilsson, L., \& Svenson, O. (2006). Driver experience and cognitive workload in different traffic environments. Accident; Analysis and Prevention, 38, 887-894.

44. Paxion, J., Berthelon, C., \& Galy, E. (2013). Does driving experience delay overload threshold as a function of situation complexity? In L. Dorn \& M Sullman (Eds.), Driver behaviour and training (Vol. VI, pp. 13-23). England: Ashgate Publishing.

45. Paxion, J., Galy, E., \& Berthelon, C. (2014). Mental workload and driving. Frontiers in Psychology, Review. https://doi.org/10.3389/fpsyg.2014.01344.

46. Peck, R. C., Gebers, M. A., Voas, R. B., \& Romano, E. (2008). The relationship between blood alcohol concentration (BAC), age, and crash risk. Journal of Safety Research, 39, 311-319.

47. Pépin, G., Jallais, C., Fort, A., Moreau, F., Navarro, J., \& Gabaude, C. (2017). Towards real-time detection of cognitive effort in driving: contribution of a cardiac measurement. Le Travail Humain, 1(80), 51-72. https://doi.org/10. 3917/th.801.0051.

48. Philip, P., Vervialle, F., Le Breton, P., Taillard, J., \& Horne, J. A. (2001). Fatigue, alcohol and serious road crashes in France: Factorial study of national data. British Medical Journal, 322, 829-830.

49. Phillips, D. P., \& Brewer, K. M. (2011). The relationship between serious injury and blood alcohol concentration (BAC) in fatal motor vehicle accidents: $\mathrm{BAC}=0.01 \%$ is associated with significantly more dangerous accidents than $\mathrm{BAC}=0.00 \%$. Addiction, 106(9), 1614-1622.

50. Sagberg, F. (1999). Road accidents caused by drivers falling asleep. Accident; Analysis and Prevention, 31, 639-649.

51. Schweizer, T. A., Vogel-Sprott, M., Danckert, J., Roy, E. A., Skakum, A., \& Broderick, C. E. (2006). Neuropsychological profile of acute alcohol intoxication during ascending and descending blood alcohol concentration. Neuropsychopharmacology, 31, 1301-1309.

52. Simons, R., Martens, M., Ramaekers, J., Krul, A., Klöpping-Ketelaars, I., \& Skopp, G. (2012). Effects of dexamphetamine with and without alcohol on simulated driving. Psychopharmacology, 222, 391-399.

53. Smit, A. S., Eling, P. A. T. M., \& Coenen, A. M. L. (2004). Mental effort affects vigilance enduringly: after-effects in EEG and behavior. International Journal of Psychophysiology, 53, 239-243.

54. Smith, S. S., Horswill, M. S., Chambers, B., \& Wetton, M. (2009). Hazard perception in novice and experienced drivers: the effects of sleepiness. Accident; Analysis and Prevention, 41, 729-733.

55. Thayer, R. E. (1986). Activation-deactivation adjective check list: current overview and structural analysis. Psychological Reports, 58, 607-614.

56. Thiffault, P., \& Bergeron, J. (2003). Monotony of road environment and driver fatigue: a simulator study. Accident; Analysis and Prevention, 35, 381-391.

57. Tiplady, B., Degia, A., \& Dixon, P. (2005). Assessment of driver impairment: evaluation of a two-choice tester using alcohol. Transportation Research Part F: Traffic Psychology and Behaviour, 8, 299-310.
58. Tricot, A., \& Chanquoy, L. (1996). La charge mentale, "vertu dormitive" ou concept opérationnel ? Introduction. Psycholologie Française, 41(4), 313-318.

59. Vakulin, A., Baulk, S. D., Catcheside, P. G., Anderson, R., van den Heuvel, C. J., Banks, S., \& McEvoy, R. D. (2007). Effects of moderate sleep deprivation and low-dose of alcohol on driving simulator performance and perception in young men. Sleep, 30, 1327-1333.

60. Van Dyke, N. A., \& Fillmore, M. T. (2017). Laboratory analysis of risky driving at $0.05 \%$ and $0.08 \%$ blood alcohol concentration. Drug and Alcohol Dependence, 175, 127-132.

61. Veldstra, J. L., Brookhuis, K. A., De Waard, D., Molmans, B. H., Verstraete, A. G. Skopp, G., et al. (2012). Effects of alcohol (BAC 0.5\%o) and ecstasy (MDMA $100 \mathrm{mg}$ ) on simulated driving performance and traffic safety. Psychopharmacology, 222, 377-390.

62. Vlakveld, W.P. (2011). Hazard anticipation of young novice drivers: assessing and enhancing the capabilities of young novice drivers to anticipate latent hazards in road and traffic situations. PhD Thesis, Rijksuniversiteit Groningen University.

63. Weafer, J., \& Fillmore, M. T. (2016). Low-dose alcohol effects on measures of inhibitory control, delay discounting, and risk-taking. Current Addiction Reports, 3, 75-84.

64. Williams, A. F. (2003). Teenage drivers: patterns of risk. Journal of Safety Research, 34, 5-15.

65. Zador, P. L., Krawchuk, S. A., \& Voas, R. B. (2000). Alcohol related relative risk of driver fatalities and driving involvement in fatal crashes in relation to driver age and gender: an update using the 1996 data. Journal of Study Alcohol and Drugs, 61, 387-395.

\section{Publisher's Note}

Springer Nature remains neutral with regard to jurisdictional claims in published maps and institutional affiliations.

\section{Submit your manuscript to a SpringerOpen ${ }^{\circ}$ journal and benefit from:}

- Convenient online submission

- Rigorous peer review

- Open access: articles freely available online

- High visibility within the field

- Retaining the copyright to your article

Submit your next manuscript at $>$ springeropen.com 